\title{
Nursing home discharges and exhaustion of medicare benefits
}

\section{Citation}

Garber, Alan M., and Thomas E. MaCurdy. 1993. Nursing Home Discharges and Exhaustion of Medicare Benefits. Journal of the American Statistical Association 88, 423:727-736.

\section{Published Version}

10.1080/01621459.1993.10476333

\section{Permanent link}

http://nrs.harvard.edu/urn-3:HUL.InstRepos:11642549

\section{Terms of Use}

This article was downloaded from Harvard University's DASH repository, and is made available under the terms and conditions applicable to Other Posted Material, as set forth at http:// nrs.harvard.edu/urn-3:HUL.InstRepos:dash.current.terms-of-use\#LAA

\section{Share Your Story}

The Harvard community has made this article openly available.

Please share how this access benefits you. Submit a story.

\section{Accessibility}


NBER WORKING PAPERS SERIES

NURSING HOME DISCHARGES AND

EXHAUSTION OF MEDICARE BENEFITS

Alan M. Garber

Thomas E. MaCurdy

Working Paper No. 3639

NATIONAL BUREAU OF ECONOMIC RESEARCH

1050 Massachusetts Avenue

Cambridge, MA 02138

March 1991

Supported in part by Grants AG07651 and AG05842 from the National Institution on Aging and by Grant 12761 from the Robert Wood Johnson Foundation. Alan Garber is a Henry J. Kaiser Family Foundation Faculty Scholar in General Internal Medicine. We are grateful to Andrew Dick for his expert assistance, and to Hilary Hoynes, Michael Cragg, and Douglas staiger for helpful comments. This paper is part of NBER's research programs in Health Economics and Aging. Any opinions expressed are those of the authors and not those of the National Bureau of Economic Research. 
NBER Working Paper \#3639

March 1991

\begin{abstract}
NURSING HOME DISCHARGES AND
EXHAUSTION OF MEDICARE BENEFITS
\end{abstract}

\begin{abstract}
The price sensitivity of demand for nursing home care is a subject of considerable policy interest. Standard methods for measuring price responsiveness are difficult to apply to nursing home care, since accurate price information is usually unavailable and prices may reflect unmeasured quality characteristics. We estimate price sensitivity by exploiting the dynamic price variation implicit in Medicare payment rules for nursing home care. We determine whether the hazard rate for nursing home discharge shifts in response to the price changes that occur when Medicare coverage diminishes or ends. Our findings provide strong evidence that the duration of nursing home admissions is sensitive to price.
\end{abstract}

Alan M. Garber National Bureau of Economic Research 204 Junipero Serra Boulevard Stanford, CA 94305
Thomas E. MaCurdy Department of Economics Encina Hall Stanford University Stanford, CA 94305-6072 
Of the many uncertainties facing potential insurers of long-term are, few are of greater importance than the price-elasticity of the demand or nursing home care. Private insurance now accounts for a small fraction If expenditures for nursing home care. If it becomes popular, and if the lemand for nursing home care is price-sensitive, then long-term care nsurance will likely stimulate rapid growth in expenditures. This sequence sf events would repeat the pattern set by expenditures for medical and 1ospital services over the past three decades. According to many experts, he dissemination of health insurance was an important cause of the fifteenold increase in per-capita health expenditures between 1960 and 1988 'Office of National Cost Estimates, 1990, p. 24). Similar observations have Indoubtedly led insurers to proceed cautiously in marketing long-term care jolicies.

There are at least two popular but disparate views about the size of the insurance subsidy effect on utilization. The first view is that lemand, and hence utilization, is likely to be price-inelastic; nstitutionalization is so unpleasant that the disabled elderly use nursing 1omes only when they require assistance in performing such basic tasks as walking, eating, and toileting, and are completely unable to live at home or with a relative. The second view is that the utilization of long-term care is sensitive to price, especially in the long run. According to this view, the lemand for nursing home services is likely to be as price-elastic as the Jemand for conventional health care, which exhibits price elasticities in the :ange of about -0.1 to -0.2 (Phelps and Newhouse, 1974; Newhouse and Phelps, 1976; Manning et al., 1987). If the second view is correct, the 
dissemination of long-term care insurance can be expected to stimulate the growth of long-term care expenditures, much as health insurance promoter rapid growth in expenditures for hospital and physician services (Pauly, 1986).

Existing empirical work offers mixed evidence regarding the importance of price effects in the utilization of nursing home care (Chiswick, 1976; Nyman, 1989). Reduced-form models are beset by difficulties in measuring the price, quality, and quantity of institutional cart Few data sets have direct measures of these variables; much of the observed variation in prices or costs simultaneously reflect differences in the quality and/or quantity of the services delivered. These measurement problems pose a significant challenge to analyses designed to estimate pric sensitivity.

The time-honored approach to estimating price effects, structural modeling, faces additional challenges. Restrictions implicit in a structural model are difficult to justify in empirical analyses of long-term care. In particular, exclusion restrictions needed to identify the structural parameters may not be satisfied. In addition, it is not even clear who makes the decision to terminate a nursing home admission. Although the patient and family usually play large roles in determining the length of stay the institution may also initiate discharges, sometimes against the objectior of the patient and family.

To overcome these limitations of conventional approaches to demand estimation, we develop an alternative method for detecting whether price is a significant determinant of the duration of nursing home 
discharge rates for nursing home stays financed by Medicare with the pattern for spells financed by other payment sources. We then investigate empirical specifications designed to detect the response of Medicare discharge rates to implicit price shifts. We close with a discussion of the implications of this analysis for the development of long-term care insurance.

\section{Payment Rules and Incentives for Discharge}

Medicare pays for a small proportion of U.S. nursing home expenditures (1.6\% in 1986), largely due to its combination of restrictive rules and limited benefits. The restrictions reflect the purpose of the Medicare nursing home benefit, which is designed to provide brief convalescence after a hospitalization, not to fund long-term custodial care. Thus Medicare pays only if the nursing home is a certified skilled-nursing facility, the admission satisfies a prior hospitalization requirement, the nursing home stay is for the treatment of the condition that was treated in the hospital, the admission is certified by a physician, and a utilization review committee does not disapprove the stay. Its modest total expenditures belie Medicare's important role in nursing home care; it covers many short-term admissions and is the initial source of payment for many admissions that are later reimbursed by other payers.

To understand the Medicare nursing home benefit, it is important to appreciate the relationship between the benefit period and the number of days of eligibility for nursing home care. The number of days of 
admissions. We do so by exploiting a source of price variation that is uncontaminated by unmeasured differences in the quality and quantity of services associated with nursing home care. We refer to the price variation that arises from special features of Medicare payment rules. If a nursing home admission qualifies for Medicare reimbursement, then Medicare will pay the full cost for the first 20 days of nursing home utilization during a benefit period. From day 21 through day 100, Medicare imposes a copayment, which often is partially covered by private "medigap" policies. "Exhaustion" of the Medicare nursing home benefit occurs at the 100th day of covered care, when Medicare and most medigap policies stop reimbursing for nursing home care. The Medicare rules imply a uniform set of temporal price changes that, in comparison to cross-sectional price variation, is free of confounding by quality differences or other unmeasured characteristics: free nursing home care for the first twenty days, then a price near 0 (for those with medigap) or near the full price (for those without such insurance), followed by full price (day 100). We use this temporal source of price variation to infer price sensitivity, estimating responses of discharge rates to the price shifts implicit in the Medicare rules.

In the next section, we further discuss the rules for Medicare coverage and how they differ from other sources of financing for nursing home care. We then describe the empirical model we developed in order to detect changes in utilization that occur as the price shifts. After presenting the methodology, we briefly describe the data set used for our analysis. In the empirical section, we first compare the time pattern of 
eligibility "runs down" from 100 beginning with the first day and continuing with all subsequent days of a Medicare-covered nursing home stay. Eligibility also runs down for readmissions to nursing homes during the same benefit period. Upon the start of a new benefit period, the number of days of eligibility is reset to 100 . While the loss of eligibility is tied to the nursing home admission, hospitalization defines the onset of a benefit period. The initial benefit period for a Medicare recipient begins the first time the individual enters a hospital while enrolled in the Hospital Insurance component of Medicare ( $\mathrm{Part} \mathrm{A})$. This and all subsequent benefit periods end after the enrollee has been out of a hospital or skilled nursing facility for 60 consecutive days. Because a Medicare-covered nursing home admission must begin within 30 days of hospital discharge, it is part of the benefit period corresponding to the preceding hospitalization. Readmission to a nursing home within one month of discharge from a hospital or Medicare-covered nursing home stay is also considered to be part of the same benefit period. Thus, if the first admission "used up" 15 days of eligibility, five days of full Medicare coverage and 80 additional days of partial coverage would be available for the readmission. If the readmission followed a hospital admission more than 60 days later, it would fail in a new benefit period. Then 20 days of full coverage and 80 days of partial coverage would be available.

During the period of copayments, supplementary private insurance (medigap) coverage confounds the price variation implicit in the Medicare payment rules. All Medicare recipients receive full coverage during the first 20 days of qualifying nursing home care in a benefit period, and nearly 
all recipients bear the full cost out-of-pocket after day 100 , since very few private supplemental policies extend the nursing home benefit beyond the Medicare ceiling (Rice and McCall, 1985). However, the two-thirds of the elderly who are covered by medigap policies pay for little or none of the copayment during days $21-100$. The remaining one-third, who are typically less wealthy, usually bear the entire copayment out-of-pocket unless they are also enrolled in Medicaid. Thus medigap coverage is an additional source of price variation during the copayment interval.

However, as a factor that influences the prices individuals face, medigap coverage is subject to the same shortcomings as cross-sectional sources of price variation. Many of the factors that influence the purchase of medigap policies, such as wealth, employment history, and attitudes toward risk, also influence nursing home utilization directly. In order to avoid the ambiguities that arise from the endogeneity of medigap coverage: we do not explicitly distinguish between medigap enrollees and nonenrollees in our empirical analysis.

Other forms of insurance coverage neither generate comparable shifts in price nor confound the Medicare payment rules. Most forms of private long-term care insurance have limits on the number of covered nursing home days, but these limits vary. Furthermore, although their availability has grown and 1.5 million such policies had been sold by the end of 1989 (Van Gelder and Johnson, 1989), private long-term care insurance has yet to play a major role in financing nursing home care (Office of National Cost Estimates, 1990). 
Other government programs neither impose substantial copayments nor end coverage after 100 days. The largest government or private program for financing long-term care is Medicaid, a need-based program that pays for about $44 \%$ of nursing home expenditures (National Center for Health Statistics, 1990, p. 237). Features of Medicaid programs vary from state to state, but none of them limit the number of days of nursing home care an enrollee can receive, nor are recipients subject to copayments. Thus, Medicaid rules for nursing home reimbursement do not lead to a price schedule that shifts at fixed times in the benefit period. Smaller government programs also provide or pay for long-term care, but direct payments by nursing home patients or their families account for most of the remaining expenditures. Patients whose admissions are financed by these sources face a price schedule that may vary because of changes in their health conditions, but does not shift abruptly at 20 or 100 days.

Consequently, of the major sources of financing for nursing home care, only Medicare generates a price schedule that shifts exogenously at fixed times. A change in discharge rates at these times implies that, for at least a subset of Medicare admissions, utilization is sensitive to price.

To determine whether nursing home utilization responds to this source of price variation, we analyze data on the duration of nursing home admissions for a sample of frail, disabled, and otherwise vulnerable elderly men and women who were believed to be likely to enter a nursing home. Although this sample is not representative of all elderly Americans, it does represent a group of particular interest: persons expected to consume a disproportionate share of long-term care. If associations between 
insurance-induced price variation and duration patterns are significant in this sample, then the relationship in the general population -- particularly those who are disabled but currently live in the community -- might be stronger, particularly if demand for nursing home care among this high-risk population is less price-elastic.

\section{Empirical Framework}

If the demand for nursing home care is sensitive to price, the shifts in price faced by patients as copayments begin and as benefits end will lead to exhaustion effects, which are changes in discharge rates that occur in response to program-induced price changes. Price sensitivity implies that discharge rates should increase near day 20 and near day 100. The Medicare rules, then, imply that the length of a nursing home admission displays particular forms of duration dependence. Our framework for assessing the impact of the implicit price change builds from standard duration analysis but accommodates very general forms of duration dependence.

If the imposition of the copayment and the termination of coverage affect nursing home discharge rates, duration dependence should be nonmonotonic. Although discharge rates are expected to increase near days 20 and 100, economic theory does not predict what will happen to discharge rates immediately thereafter. Discharge rates could increase if, for example, underlying patient heterogeneity is unimportant, so the increased marginal cost causes the daily discharge rate to be high. 
Discharge rates could also fall; if patient heterogeneity is important, and if many patients whose demand for nursing home care is highly price-elastic depart at day 20 , the remaining patients may have less elastic demand and lower exit rates. At day 100 , there should be another increase in discharge rates in response to the complete removal of Medicare benefits (and usually the termination of supplementary private insurance benefits). Only an empirical model that accommodates general forms of duration dependence, then, can detect the changes in discharge rates that are expected to result from these price shifts.

Consider the distribution describing the length of stays in nursing homes, which represents the number of days of continuous residence in the nursing home given admission to the institution. Denote the duration of a nursing home stay (in days) by $\tau$. The probability density function for nursing home spells, $f(\tau)$, is related to a survivor function, $S(\tau-1)$, by

$$
f(\tau)=S(\tau-1)[1-P(X, \tau)],
$$

with

$$
S(\tau-1)=\prod_{t=1}^{\tau-1} P(x, t)
$$

and where $P(X, t)$ represents the probability of "surviving" (remaining in the nursing home) a single time period, conditional on the values of $X$ and $t$. The variables $X$ include factors influencing the length of a spell, such as gender and age, which are fixed at the time of entry into the nursing home. The quantity $\tau$ represents the number of days spent in the nursing home as 
of the time of evaluation. If $P(X, t)$ increases (decreases) as a function of $t$, then positive (negative) duration dependence is said to exist.

Plots of hazard rates are a familiar mechanism for characterizing the nature of duration dependence. The hazard function is defined as

$$
h(\tau)=\frac{f(\tau)}{S(\tau-1)}=1-P(X, \tau),
$$

which represents the fraction of the institutional population that will exit or the rth day of admission, given that they have been in the nursing home for $r-1$ days. Graphs of $h$ provide a format for testing the theoretical prediction that exhaustion effects are present. Standard empirical specifications typically do not accommodate nonmonotonic duration dependence, which is an essential feature of exhaustion properties. Furthermore, they do not allow for interaction between the form of duration dependence and covariates $X$.

To allow for flexibility in the form of duration dependence and in its relation to the covariates, and to be able to detect the effects of exhaustion of Medicare benefits, we specify the following model for the survival probabilities $P(X, t)$ :

$$
P(X, t)=\frac{1}{1+e^{X_{1} B+g\left(t, X_{2}\right)+c(E-t)+m(E-t)}},
$$

where $X_{1}$ and $X_{2}$ are vectors of variables included in $X$, and B is a parameter vector. The variable $E$ is the number of days of eligibility for Medicare nursing home coverage remaining in the benefit period, as of the date of admission to the nursing home. For the first admission during a 
benefit period, $E$ must always equal 100 , but for subsequent admissions the number of covered days used previously in the benefit period must be subtracted. The exponential term in the denominator of (4) includes the terms:

$g\left(t, x_{2}\right)=\sum_{j=1}^{k_{g}}\left[\Phi_{1 j}^{g}(t)-\Phi_{2 j}^{g}(t)\right]\left[\alpha_{0 j} x_{2}+\alpha_{1 j} t+\alpha_{2 j} t^{2}\right]$

$:(E-t)=\sum_{j=1}^{k_{c}}\left[\Phi_{1 j}^{c}(E-t-80)-\Phi_{2 j}^{c}(E-t-80)\right] \gamma_{c j}$,

$a(E-t)=\sum_{j=1}^{K_{m}}\left[\Phi_{1 j}^{m}(E-t)-\Phi_{2 j}^{m}(E-t)\right] \gamma_{m j} \cdot$

The quantity $\boldsymbol{\Phi}_{i j}(t)$ denotes the cumulative distribution function of a normal random variable having mean $\mu_{i j}$ and variance $\sigma_{i j}^{2}$. The coefficients $\alpha_{i j}$, $\gamma_{c j}$, and $\gamma_{m j}$ represent parameter vectors. Equation (4) models $P$ as a logit function.

The functions $g\left(t, X_{2}\right), c(E-t)$, and $m(E-t)$ are spline terms that capture critical aspects of duration dependence. The term $g$ determines the general features of the duration distribution of nursing home admissions, allowing for interaction with the variables included in $X_{2}$. The terms $c$ and $m$ are designed to capture changes in the hazard rate as the copayment is imposed or the cap on Medicare nursing home benefits is reached. These splines are very general, admitting varying degrees of smoothness and increasing, decreasing, or nonmonotonic forms of duration dependence. 
Standard splines allow for the best-fitting polynomials over intervals, with equality constraints on the values of the functions and on their derivatives at "knots," or the points where one polynomial begins and another ends. Our spline formulation allows for several polynomials, but they do not begin at one point and end abruptly at another point. Instead, the polynomials begin and end gradually according to the properties of the cumulative normal functions $\Phi_{1 j}$ and $\Phi_{2 j}$.

To illustrate the characteristics of these splines, we consider the properties of the function $r(t) \equiv\left[\Phi_{I j}(t+a)-\Phi_{2 j}(t+a)\right]$, which is a representative component of the linear combinations making up $g, c$, and $m$. Figure 1 plots three formulations of $r$. All specifications set $\mu_{l j}=a-10$ and $\mu_{2 j}=a+10$, so $r(t)$ contributes to a function that spans at least the range of $(\mathrm{a}-10, \mathrm{a}+10)$. In one of the specifications, $\sigma_{i j}=\sigma_{2 j}=0$ (or equivalently sets $\sigma_{1 j}$ and $\sigma_{2 j}$ to small values), so $r(t)$ abruptly shifts from 0 to 1 at day a-10, remaining at 1 from a-10 to a+10 days, and immediately drops from 1 to 0 at day $a+10$. A second specification enlarges the standard deviations to the values $\sigma_{l j}=\sigma_{2 j}=2$, which induces a less abrupt transition of $r(t)$ from 0 to 1 around the points $\mathrm{a}-10$ and $\mathrm{a}+10$. The third formulation of $r(t)$ expands $\sigma_{1 j}$ and $\sigma_{2 j}$ even further to the value 5, which produces a more gradual shift in $r(t)$ operating over the range a-25 to $a+2$. days. Thus, as Figure 1 illustrates, the values of $\mu, a$, and $\sigma$ determine the region over which functions such as $r(t)$ operate. The values of $\sigma$ also dictate the smoothness of their influence.

The function $g$ consists of linear combinations of quantities analogous to $r(t)$ multiplied by polynomials that are linear in the covariates 
$X_{2}$ and quadratic terms in $t$. Thus, if for one of the components $\left[\Phi_{l j}(t)-\right.$ $\left.\Phi_{2 j}(t)\right]$ of $g$, the parameters $\mu_{l j}=t_{1}$ and $\mu_{2 j}=t_{2}$ with $\sigma_{l j}=\sigma_{2 j}=0$, then $g$ equals $\alpha_{0 j} X_{2}+\alpha_{l j} t+\alpha_{2 j} t^{2}$ over the interval from $t_{1}$ to $t_{2}$. Because the $\sigma$ terms are small, there could be abrupt changes in the value of $g$ at the endpoints $t_{1}$ and $t_{2}$. If instead, $\sigma_{l j}$ and $\sigma_{2 j}$ are set to higher values, there will be gradual transitions from one polynomial to another. In summary, the formulation of $g$ given by (5) implies that the number of intervals that have different polynomials is determined by setting $K_{g}$; their endpoints are determined by the $\mu$ terms; and the smoothness of transition between the intervals is determined by the values of $\sigma$. Note that, unlike the knots in a conventional spline, not every point in time needs to fall within an interval $\mu_{1 j}-\mu_{2 j}$ for some $j$. Furthermore, the function $g\left(t, X_{2}\right)$ is differentiable in $t$, and its specification allows for the effects of the variables included in $X_{2}$ to be fully interacted with duration.

The splines $m(E-t)$ and $c(E-t)$ are similar to $g$, but are functions of the number of days of eligibility remaining in the benefit period and the number of days remaining until the copayment begins, respectively. They account for exhaustion effects or changes in the hazard rates that occur when the copayment begins or when benefits terminate; $E-t$ is the number of days of Medicare eligibility remaining at time $t$. The $\mu_{i j}$ and $\sigma_{i j}$ terms that parameterize the cumulative normal functions ( $\Phi$ functions) in $c(E-t)$ allow this function to be nonzero at values of $t$ near 20 days of care during a Medicare benefit period. For the $m$ terms, $\mu_{l j}$ and $\mu_{2 j}$ are defined in relation to day 100 of nursing home duration in the benefit period. Thus, if $\mu_{11}$ in $c$ is -5 , it corresponds to day 15 of nursing home use; and if $\mu_{11}=-5$ 
in $m$, it corresponds to day 95. The specifications listed in (5) admit a wids range of options for the functions $c(E-t)$ and $m(E-t)$. As in the previous example, varying the values of the $\mu_{i j}$ terms relocates the splines, and adjusting the values of the $\sigma_{i j}$ terms determines the smoothness of the splines.

Consider, for example, a specification of $c(E-t)$ in which $K_{c}=2$, $\mu_{11}=-5, \mu_{21}=\mu_{12}=0$, and $\mu_{22}=5$, and the standard deviations are set at very small values. This specification implies that $c(E-t)=\gamma_{c l}$ from five days prior to the imposition of the copayment up to the day the copayment begins, and $c(E-t)=\gamma_{c 2}$ for five days after the copayment begins. If $\gamma_{a}>$ 0 and $\gamma_{c 2}=0$, then the hazard rises just prior to the start of copayment and returns to its original level afterward. Such a finding would support the existence of an exhaustion effect because it indicates an increased rate of exit from nursing homes as full coverage for expenses ends.

The function $m(E-t)$ is designed to capture similar phenomena occurring near day 100. The $\mu_{i j}$ and the $\sigma_{i j}$ terms applicable in forming this function permit $m$ to be nonzero at values of $t$ near 100 days of nursing home care in a benefit period, when benefits terminate. If the means are placed in positions analogous to those in the above example of $c(E-t)$, the function $m(E-t)$ would have the properties $m(E-t)=\gamma_{m l}$ from days 95 to 100 , and $m(E-t)=\gamma_{m 2}$ from the day coverage ends until five days later. Exhaustion effects would be present if $\gamma_{m l}>0$.

For the analyses we report below, the values of $K_{g}, K_{c}, K_{m}$, and each of the $\mu$ and $\sigma$ parameters in the splines $g, c$, and $m$ are fixed. We choose the values of these quantities to capture the basic properties of 
empirical hazards revealed in exploratory data analysis and to provide for flexibility in detecting theoretical predictions. ${ }^{1}$ With these quantities fixed, the functions $g, c$, and $m$ are each differentiable in $t$ and are strictly linear in the unknown coefficients $\alpha$ and $\gamma$, which are estimated in the analysis.

\section{Data from the National Long-Term Care Demonstration}

Our data were obtained as part of the National Long-Term Care (Channeling) Demonstration, a large-scale randomized trial that was organized in 1980 by the Department of Health and Human Services in order to test an intervention called "case management." The intervention was designed to improve access to home health care and other communitybased long-term care services, thereby reducing nursing home utilization. The demonstration enrolled a group of high-risk elderly participants at ten sites around the country. The intervention was unsuccessful; it did not significantly alter nursing home utilization or improve functional status or objective measures of health. Consequently, our analyses do not incorporate estimates of the effect of case management. The design and execution of the trial and a description of its findings are the subjects of a special issue of Health Services Research (April 1988).

To participate in the study, an individual had to be at least 65 years old; suffer limitations in basic activities of daily living (ADL) or

${ }^{1}$ In the empirical analyses, the results were not sensitive to the number of splines or the values of the $\sigma$ terms, although models that incorporated spline terms capable of detecting changes in the hazard rates near days 20 and 100 fit best. 
instrumental activities of daily living (IADL); and have unmet needs, meaning that because of functional impairments he or she required help with at least two categories of service for six months. Persons who were ir nursing homes at the time of enrollment were only included if discharge was likely within three months. The sample meeting these criteria was relatively old (mean age 80 ), ill-educated, poor, and disabled. Baseline data were collected from 5,626 individuals between September 1982 and July 1983. Followup information came from interviews conducted 6, 12 , and 18 months following the enrollment period.

A large percentage of participants entered nursing homes, often for repeated stays. About $16 \%$ of the participants entered a nursing home during the first year, and during the entire followup period, nearly 1,000 had at least one admission; 292 had at least two admissions, 93 had at least 3 , and 20 had four or more admissions. Medicare paid for part of the cost for $43 \%$ of the first spells; Medicaid was the sole initial payer for $26 \%$ of spells, and other payers were responsible for $31 \%$. The proportion coveres by Medicare or others fell steadily with admission number; Medicaid was the payer for $50 \%$ of third and $60 \%$ of fourth admissions.

Table 1 lists variables names, definitions, and summary statistics stratified by primary payment source at the time of admission. It shows that, with a few important exceptions, key characteristics of patients admitted to nursing homes under each payment source were similar. In general, this was an elderly population, and between $20 \%$ and $30 \%$ of the entrants were male. Severe ADL impairments were extremely common, affecting about $75 \%$ of the spells, and approximately $40 \%$ of the nursing 
home entrants lived alone. The mean ages and prevalence of severe impairments activities of daily living $(\mathrm{SVADL}=1)$ was nearly the same in the three payer groups, although severe dementia (DEMENTIA $=1$ ) was most common in the "other payer" group. Multiple spells were most common for Medicaid admissions, and the number of second spells was intermediate for other payment sources.

A slightly higher percentage of all nursing home admissions were financed by Medicare than by the other two payment sources. Few of the Medicare admissions were interrupted by the end of the study--only $9 \%$ of the Medicare spells were right censored, as compared with $39 \%$ of the Medicaid-financed spells and $21 \%$ of the spells paid by other sources. As noted in Section I, we do not include indicator variables for medigap coverage in our empirical analysis because such variables are endogenous. Medigap purchase reflects a number of unobserved or poorly measured characteristics that have direct effects on nursing home utilization. Including medigap as an explanatory variable would introduce a nonexogenous source of temporal price variability. In order to ensure that temporal price shifts present in our data arise from exogenous sources, we do not distinguish between individuals who have and do not have medigap coverage. The resulting estimates of the impact of price shifts at day 20 are downwardly biased and can be considered lower bounds. 


\section{Empirical Results}

To detect the duration effects implicit in the Medicare payment structure, we implement three progressively more general sets of specifications In our initial specification, we compare the duration distributions corresponding to each of the three payer types. In the second set of specifications, we generalize the duration distribution associated with Medicare admissions by adding covariates to account for remaining eligibility and other measures of prior nursing home utilization. Our final specifications directly test for exhaustion effects.

For each specification, we apply standard maximum likelihood methods to estimate the parameters of the distribution $f(\tau)$, taking right censoring into account. The parameters include the coefficients $B$ and $\alpha$ in (4), and, where applicable, $\gamma_{\mathrm{c}}$ and $\gamma_{\mathrm{mj}}$. The units of observation are nursing home spell lengths.

\section{A. Duration of Nursing Home Admissions by Payer Type}

The effects of price shifts induced by the Medicare payment schedule should be reflected in the hazard rates. However, to be confident that any change in the hazard is unique to Medicare, it is necessary to compare the characteristics of hazards for Medicare spells with those for other payers, which do not induce similar temporal price shifts. To do so, we assign each nursing home spell to one of three payers, based on the 
payment source(s) at the time of admission. If Medicare paid any part of the nursing home costs initially, it is considered to be the payer. If Medicaid, but not Medicare, paid any of the costs of the admission at the time of entry, Medicaid is considered the payer. "Other payer" is the payment source if neither Medicare nor Medicaid contributed to the nursing home payments at the time of admission. Thus an individual who "spent down" to Medicaid eligibility during a nursing home admission is not considered a Medicaid patient during that admission.

Table 2 presents coefficient estimates and standard errors for $f(\tau)$ associated with each of the three payment sources. The specification has the form of (4), with the functions $c(E-t)$ and $m(E-t)$ excluded. In this specification, $X_{2}=1$, while $X_{1}$ includes dummy variables that indicate source of entry (hospital or home), sex, living arrangement, dementia, and severe impairment in the ability to perform a basic activity of daily living, as well as age (and age squared). For the most part, these and other explanatory variables tested in preliminary analyses (including other specifications for dementia; education; marital status; presence of children nearby; other specifications of living arrangements; and ethnic variables) are statistically insignificant. ${ }^{2}$ With the exceptions of dementia, which significantly prolongs duration for Medicaid spells and has borderline statistical significance for Medicare spells, and sex (men have shorter spells for each of the payment sources), none of the variables are statistically significant for more than one type of payment source. Note that a positive

${ }^{2}$ Inclusion of financial variables, such as income, does not alter any of the conclusions below. 
coefficient implies that a decrease in $P$, and therefore a decrease in the duration of the admission, is associated with an increase in the value of the corresponding variable. While most of the individual spline terms are insignificant, they are jointly significant for each of the payer types.

Figure 2 shows that the levels of the hazard vary substantially by payer. The hazard rate for Medicare-financed admissions is uniformly 2-3 times as great as for Medicaid admissions. The peak value of the daily discharge rate reaches nearly $3 \%$ for Medicare-financed admissions at about the 25 th day of admission but only about $1 \%$ for Medicaid-financed admissions. Although the peak for "other payer" admissions is sharper than for Medicaid, the average level of the hazard rate for the first 70 days or so is similar to that for Medicaid-financed admissions. A greater hazard rate implies a shorter length of stay. The median durations corresponding to these models is approximately 31 days for a Medicare-financed admission and 111 days for a Medicaid admission. Not only are the hazards for Medicare admissions everywhere higher than for the other two sources of payment, with correspondingly shorter lengths of stay, but they also increase substantially near the time that the copayment takes effect for first spells. 3

${ }^{3}$ The payment source is associated with differences in the outcome of the admission as well as its duration. In a previous paper (Garber and MaCurdy, 1991), we reported that nursing home stays are most likely to have a favorable outcome -- return to the community rather than hospital transfer or death -- if "other sources" pay for the admission. The chance that admission terminates in community discharge is less than half as great for Medicaid admissions, and decreases as the length of stay increases. 
The hazard curves for Medicare spells plotted in Figure 2 follow a pattern consistent with a price shift at day 20 . The daily discharge rate steadily rises to reach a peak at the time that the copayment begins, then gradually falls. Yet while such price variation is present only for episodes of care financed by Medicare, the hazard rates for the two other payment sources exhibit similar properties. Furthermore, the 20-day and 100-day durations are relevant only for first spells in the benefit period, yet about $20 \%$ are readmissions. There is also no evidence that the pending loss of Medicare eligibility for nursing home care at 100 days has any impact on the length of Medicare episodes. Because the spline functions smooth over a wide time interval and do not include the number of days of eligibility remaining at the time of evaluation, these empirical specifications are not sensitive to changes in discharge rates that occur near the hundredth day. We therefore investigate alternative approaches to evaluate how discharge rates change in response to payment schedules.

\section{B. Accounting for the Effects of Eligibility on Discharge Rates}

Incorporating measures of eligibility as covariates in the above model is a simple modification that might overcome the discrepancy between the duration of the individual nursing home admission and the number of covered nursing home days in the benefit period, thereby revealing the impact of declining eligibility on discharge rates for Medicare admissions. To detect shifts in hazards attributable to Medicare eligibility, we include in $X_{2}$ a direct measure of eligibility $(E)$ at the time of admission. 
As a covariate in $X_{2}, E$ is fully interacted with duration, so its effects can vary with duration. We also include in $X_{2}$ another measure of previous utilization, a dummy variable for any prior nursing home admissions withi the benefit period (2NDSPELL). These specifications continue to excludt the functions $c(E-t)$ and $m(E-t)$ from (5). To obtain the measures of $E$ at 2NDSPELL assigned to each spell, we establish when a new benefit perio begins for each person admitted to a nursing home, and infer the number of days of eligibility for nursing home care available on the day of entry $f_{\text {f }}$ each admission. If $E$ is less than $100,2 N D S P E L L$ takes the value of unit.

Estimation results for these specifications appear in Table 3. Th parameter estimates for the $X_{1}$ variables reported in this table are broadl: similar to those in Table 2. The variables $E$ and $2 N D S P E L L$ are neither individually nor jointly significant. Of the included variables, only dement is of even borderline significance. The linear time term, however, is statistically significant for the interval beyond 50 days.

Figure 3 plots the hazard functions corresponding to the specification used in section A ("basic model") and the expanded specification ("utilization model") considered in this section. The hazard rates are quite similar when eligibility is included in $X_{2}$.

The relationship between the variables and the distribution of length of Medicare-financed stays can be appreciated more readily by examining Table 4. The baseline variable values are for a representative person, and each row of the table shows the effects of changing each variable value, one at a time, on the estimated distribution of the duratio 
of an admission. The median lengths of stay are remarkably insensitive to changes in the variable values, but the upper tail changes substantially. For example, the 90th percentile of predicted length of stay increases from 125 days for a 75 -year-old who enters from the hospital to 218 days for an individual with dementia who enters from the community. It is only in the upper tails that changes in variable values have marked effects on the duration distribution, and even here the impact is limited to a subset of the variables.

This specification is designed to detect eligibility effects, but it implies that loss of eligibility has ambiguous effects. At the lower percentiles, declining eligibility is associated with shorter lengths of stay, while at the upper percentiles, the opposite relationship is observed. Neither the hazard rate nor median length of stay changes significantly as remaining eligibility declines, and the upper percentiles change in the wrong direction, suggesting that exhaustion effects are misspecified in a model that simply treats these factors as explanatory variables in a linear function. The structure of Medicare rules implies that the linear specification is inappropriate, since the consumer price of nursing home care does not change linearly with eligibility, but makes discrete changes at known times.

\section{Incorporating Exhaustion Splines}

To revise the empirical specification to detect the response of discharge rates to the jumps in price that occur when the copayment begins 
and benefits are exhausted, we test the complete specification (4), incorporating the $c$ and $m$ splines. The unrestricted version of (4) explicitly admits flexible functional forms for the hazard rates at the times that price changes occur. In this expanded specification, the covariates are the ones included in the "basic" model reported in Section A. We do not present the estimates of the coefficients for the explanatory variables included in $X_{1}$ and $X_{2}$ in subsequent discussions; their magnitudes and patterns of statistical significance are similar to the results presented in Table 3. Our interest centers on changes in hazard rates that occur near the onset of the copayment and the exhaustion of benefits.

Table 5 presents the results for this specification. The left column of the table lists the location and characteristics of the polynomials making up these splines. Columns labeled "Model I" contain estimates for unrestricted splines (six splines around points $(E-t-80)$ and $(E-t))$, while those labeled "Model II" correspond to a specification in which there is a single exhaustion spline centered at 20 days and a second spline centered at 100 days. Model III is a more restrictive specification in which the spline centered at 20 days is removed. The first line in model I, for example, gives the maximum likelihood estimates of the values of $\gamma_{c}$ and $\gamma_{m}$ for the $c$ and $m$ splines, respectively, that range from 9 to 3 days before the copayment begins or the benefit ends. When $E=100$, these correspond to day 11 to day 17 for the $c$ spline, and day 91 to day 97 for the $m$ spline. The standard deviations for the cumulative normal functions corresponding to each of these end points are 5 and 2, respectively. 
The hazard function corresponding to Model I is plotted in Figure 4. The $c$ splines in Model I are neither individually nor jointly statistically significant. In contrast, the $m$ splines located from days 98 to 100 and from days 99 to 101 are jointly significant. Splines more distant from day 100 are not statistically significant. These results imply that the best fitting specifications are those that have spline terms tightly centered at the day of exhaustion of Medicare benefits. Consequently, for model II, we excluded all splines except the ones spanning days 19 to 21 and those spanning days 99 to 101. In these specifications, the standard deviations for the cumulative normal functions are assigned small values. The spline centered at 20 days remains statistically insignificant, but the spline centered at day 100 is highly significant, with a t statistic exceeding 5 . The exclusion of the other splines from the model only results in a slight deterioration in the value of the log of the likelihood function. Excluding the $c$ spline altogether, as in model III, results in a specification that fits nearly as well.

Figure 5 plots hazard functions corresponding to models II ( $c$ and $m$ splines) and III ( $m$ spline only). The significant duration effects that occur upon termination of Medicare nursing home benefits are clearly visible here, supporting the presence of exhaustion effects. The very tight fit of the spline near day 100 is unlikely to reflect factors unrelated to the structure of the Medicare payments.

In absolute terms, the increase in hazard rates is not large, because most Medicare-financed admissions, end before benefits terminate. Nearly $74 \%$ of Medicare admissions terminate before day 19 , and only $16 \%$ remain as of day 100 . The number of persons "at risk" for discharge is so 
depleted by day 100 that, even though the hazard rate increases by a factor of five, the excess number of persons who leave because of benefit exhaustion represents only about $1 \%$ of the admission cohort. Thus the exhaustion effect explains a small fraction of variation in Medicare usage.

To test whether these exhaustion effects are unique to nursing home spells financed by Medicare, we estimated analogous specifications for spells financed by Medicaid and by other payers. ${ }^{4}$ Unsurprisingly, exhaustion effects are not observed for the other payer types. The marginal cost of an additional day of nursing home care does not change in such a predictable fashion for spells financed by out-of-pocket payment. Individuals whose expenditures approach the level that would enable them to qualify for Medicaid as "medically needy" would also face a shifting price schedule, but the relationship between duration and the price shift would vary across individuals. Once they became covered by Medicaid, they would face a zero price; the daily amount the program pays on their behalf does not vary with the total utilization of nursing home benefits. Consequently, our findings strongly suggest that the increase in discharge rates observed for Medicare patients truly represents response to a price shift. Because these effects are manifested as nonmonotonic duration dependence, many of the more familiar methods for duration analysis could not detect them.

${ }^{4}$ Because "eligibility" is an irrelevant concept for these payer types, we assume $E=100$ at the onset of these spells. 


\section{Implications for Price Effects}

The above analysis demonstrates that utilization is sensitive to price for Medicare admissions. However, this method does not produce conventional price elasticities. Unlike the kinds of price variation presumed in cross-sectional analyses, the temporal price variation implicit in Medicare rules does not represent shifts in price schedules, but rather movements along schedules; at day 20 or day 100 , the price increases from zero to some positive number, implying that there is an infinite percentage change in the price at that point. Although this implies that we cannot produce conventional demand elasticities, the duration analysis allows us to estimate the change in quantity corresponding to a regime change. That is to say, our results can be used to predict changes in the duration of a nursing home stay that result as the Medicare copayment or the limit on benefits is removed.

To estimate these regime effects, we use the estimates obtained in Model II to predict duration distributions that condition on already having been in a nursing home for a specified number of days. The predicted duration distribution corresponding to removal of the copayment is obtained by taking the limit of (5) as $E \rightarrow \infty$. The quantity effects of a regime change can be seen by comparing the duration distributions with and without the spline terms.

Our duration estimates for Model II are based on analysis of a population that includes a mixture of medigap enrollees and patients who do not have supplemental insurance. Thus, only a subset of the patients 
faced a copayment. Because the $c$-spline terms are estimated from a mixed population, the mean duration will increase more if a regime change is applied to a population that lacks coverage for the Medicare copayment. A regime change that consists of removing or raising the ceiling on Medicare benefits does not pose the same problems since medigap plans infrequently extend benefits.

Table 6 presents the means and medians under the various regimes for the distributions conditioning on being in a nursing home at days 0,17 , and 95 of a single spell. The means differ substantially from the medians because of the highly skewed nature of the conditional duration distributions. If the Medicare limits are removed -- i.e., if both the patient's share of the payment and the ceiling on the number of days of coverage are removed -- the expected number of days remaining in the nursing home spell, as of day 17 , changes by approximately $3 \%$. However, if we assume that two-thirds of the individuals did not face a change in copayment because they had medigap coverage, the change is $9 \%$. Unsurprisingly, the change in the conditional distribution at 95 days resulting from removal of the ceiling benefits is more substantial, boosting the mean by $14 \%$ and the median by $27 \%$. Thus, although these numbers cannot be interpreted as price elasticities, they indicate that the regime changes are associated with substantial changes in length of stay in nursing homes. 


\section{Conclusions}

Our finding of a striking increase in hazard rates at the time of termination of the Medicare nursing home benefit is intriguing. Although we are confident that this phenomenon represents price sensitivity, these results cannot be used to obtain exact estimates of the price elasticity of demand for nursing home care, either for the Medicare-financed nursing home spells, or for the population of nursing home residents more generally, because there is no price variation during the first 20 days. Furthermore, the price after the imposition of the copayment, which may vary across individuals, is not observed. Finally, if important unmeasured patient characteristics affect discharge rates, the price elasticity of demand for additional days of nursing home care would be different at 0 days, 100 days, and 200 days, simply because the characteristics of the population of nursing home patients remaining change with duration.

Although the increased hazard rate can be interpreted as a demand phenomenon, it may also reflect nursing home behavior. It is likely that the nursing homes initiated many of the discharges. Many nursing homes might have been content to receive the Medicare payment, along with private supplemental insurance payments during days 20-100, despite fear that the patient might fail to pay the copayment. However, uncertainty about the ability of patients to pay might motivate nursing homes to try to bring about discharge after 100 days of care, when neither Medicare nor private insurance would reimburse them. The ability of the 
nursing home to induce a nursing home discharge is constrained by the patient's health and the availability of social supports.

Despite its limitations, this study reveals important findings that could not be detected reliably with conventional methods. Our investigation of the consequences of price variation induced by the Medicare rules suggests that utilization is price sensitive. We found a sharp and statistically significant increase in discharge rates at the time when Medicare nursing home benefits are exhausted. No analogous phenomenon was apparent for nursing home stays initially financed by other payers.

The change in discharge rates is unlikely to be due to other factors, such as changes in health or functional status. Health and social supports could change at any time during a nursing home admission, and they would not be particularly likely to change after 100 days in the benefit period. The effect at 20 days was less pronounced, and was not clearly different for nursing home spells financed by Medicaid or other sources. The lack of a unique and pronounced increase in discharge rates at 20 days, despite the beginning of the imposition of the Medicare copayment, reflects our inability to control for the effects of supplemental insurance policies, which nearly always pay the copayments, but infrequently extend the period of nursing home benefits beyond the hundred days covered by Medicare. Omission of medigap coverage implies that we underestimate price sensitivity. However, had we included a medigap variable, the estimates would have been subject to bias due to the endogenous nature of the purchase of private supplemental insurance. 
Our analyses of the exhaustion effects are based on time units of days of nursing home use during a particular benefit period. Because there can be multiple nursing home admissions in each benefit period, the phenomena observed at day 100 could be occurring at any number of days during a particular admission to a nursing home. This tends to confirm the interpretation that what is observed is an economic phenomenon, particularly since our analysis reveals that the spell number does not matter. Furthermore, these effects are much less pronounced in analyses that use time in the nursing home spell rather than the cumulative number of days of care in the benefit period that has been used.

Rough calculations indicate that the duration of Medicare-financed admissions is sensitive to price. The estimated mean duration of all Medicare nursing home admissions would increase by about $6 \%$ if the copayment and the limit on the benefit were removed. Our analyses do not provide estimates of conventional price elasticities, which would require direct price information. Although these results need to be confirmed in a more representative population before we can be confident that they apply to the elderly in general, our study provides strong evidence that utilization of nursing home care is likely to be price-elastic. 


\section{References}

Chiswick, Barry R. 1976. The demand for nursing home care: an analysis of the substitution between institutional and noninstitutional care. Journal of Human Resources, Vol 11, No. 3, (Summer), pp. 295316.

Garber, Alan M., and MaCurdy, Thomas. 1991. Payment source and episodes of institutionalization. (In press in Wise, David (ed.). New Directions in the Economics of Aging, University of Chicago Press.)

Manning, Willard G., Newhouse, Joseph P., Duan, Naihua, Keeler, Emmett B., Leibowitz, Arleen, and Marquis, M. Susan. 1987. Health insurance and the demand for medical care: evidence from a randomized experiment. American Economic Review, Vol. 77, No. 3, (June), pp. 251-277.

National Center for Health Statistics. Health United States 1989. 1990. U.S. Department of Health and Human Services, Public Health Service, Centers for Disease Control, National Center for Health Statistics, Hyattsville, MD (DHHS Pub. No. (PHS) 90-1232).

Newhouse, Joseph P., and Phelps, Charles E. 1976. New estimates of the price and income elasticities for medical care services. In Rosett, Richard, (ed.), The Role of Health Insurance in the Health Services Sector, New York: National Bureau of Economic Research.

Nyman, John A. 1989. The private demand for nursing home care. Journal of Health Economics, Vol 8, No. 2 (June), pp. 209-231.

Office of National Cost Estimates, Office of the Actuary. 1990. National Health Expenditures, 1988. Health Care Financing Review, Vol.11, No. 4 (Summer), pp. 1-41.

Pauly, Mark V. 1986. Taxation, health insurance, and market failure in the medical economy. Journal of Economic Literature, Vol.24, No. 2 (June), pp. 629-675. 
Phelps, Charles E., and Newhouse, Joseph P. 1974. Coinsurance, the price of time, and the demand for medical services. Review of

Economics and Statistics, Vol. 56, No. 3 (August), pp. 334-342.

Rice, Thomas, and McCall, Nelda. 1985. The extent of ownership and the characteristics of Medicare supplemental policies. Inquiry, Vol 22, No. (Summer), pp. 188-200.

Van Gelder, S, and Johnson, D. 1989. Long-Term Care Insurance: Market Trends, Washington, D.C.: Health Insurance Association of America.

Wooldridge, Judith, and Schore, Jennifer. 1988. The effect of channeling on the use of nursing homes, hospitals, and other medical services. Health Services Research, Vol. 23, No. 1 (April), pp. 119-27. 
Table 1. Sumary statistics by Payment Source

Variable

Mean std. Dev. 1 Min.

$25 \%$

$50 \%$

$75 \%$

Max.

Medicare Spells: number of spells $=542$

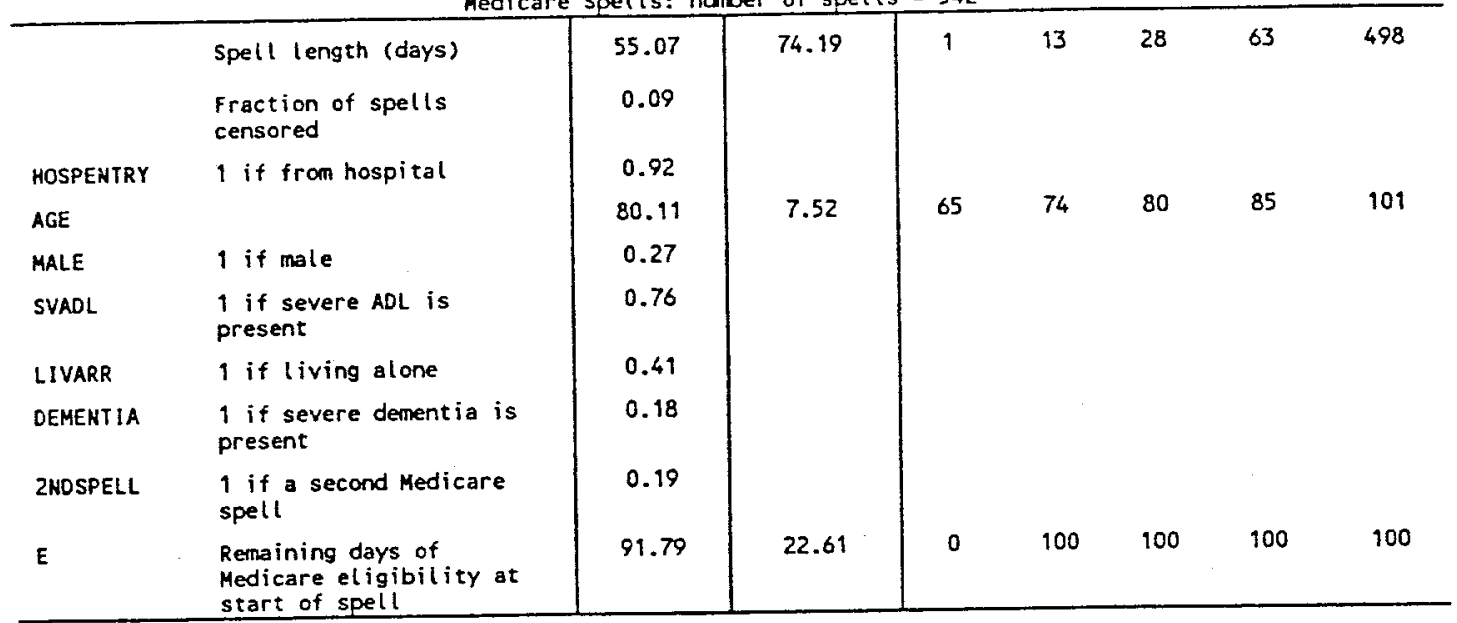

Medicaid Spells: number of spells $=424$

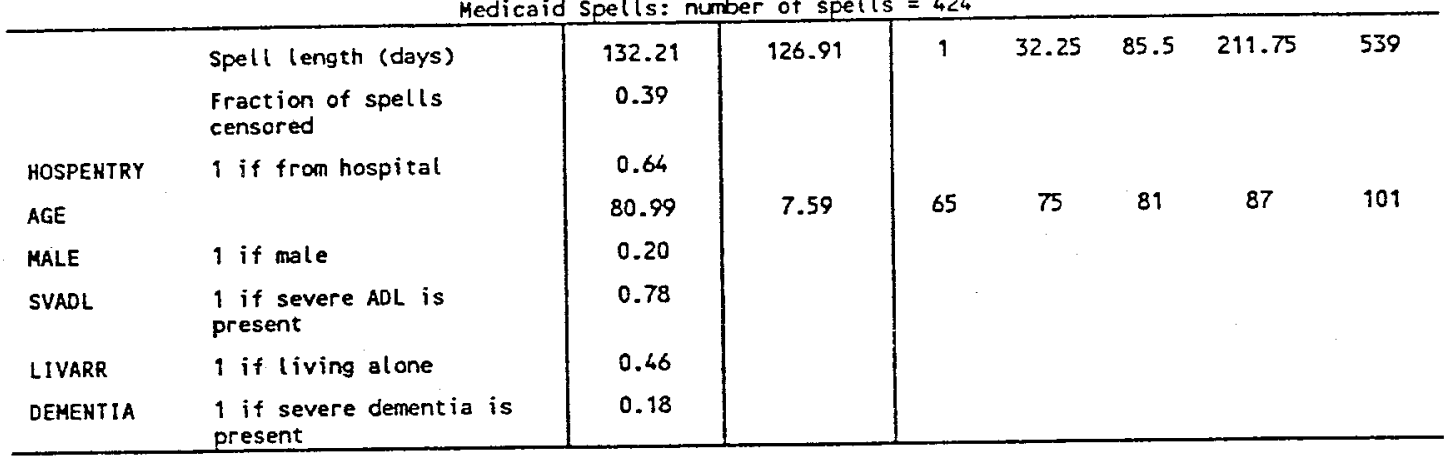

Other Payer Spells: number of spells $=424$

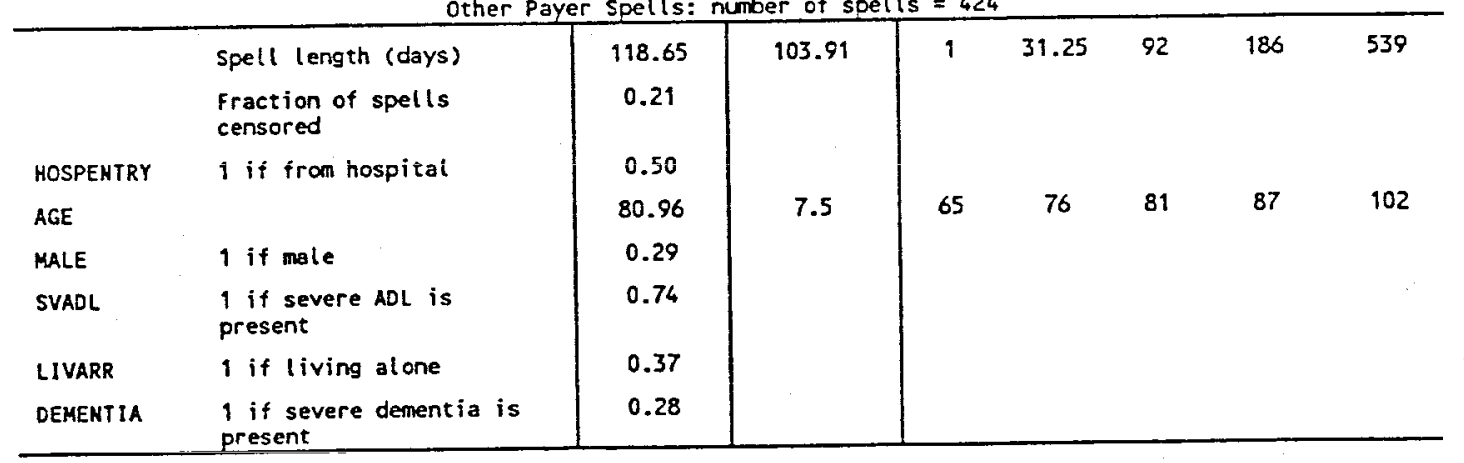


TABLE 2. Parameter Estimates of Nursing Home Spell Duration Probabilities $\mathrm{P}(\mathrm{X}, \mathrm{t})$ (Standard Errors in Parentheses).

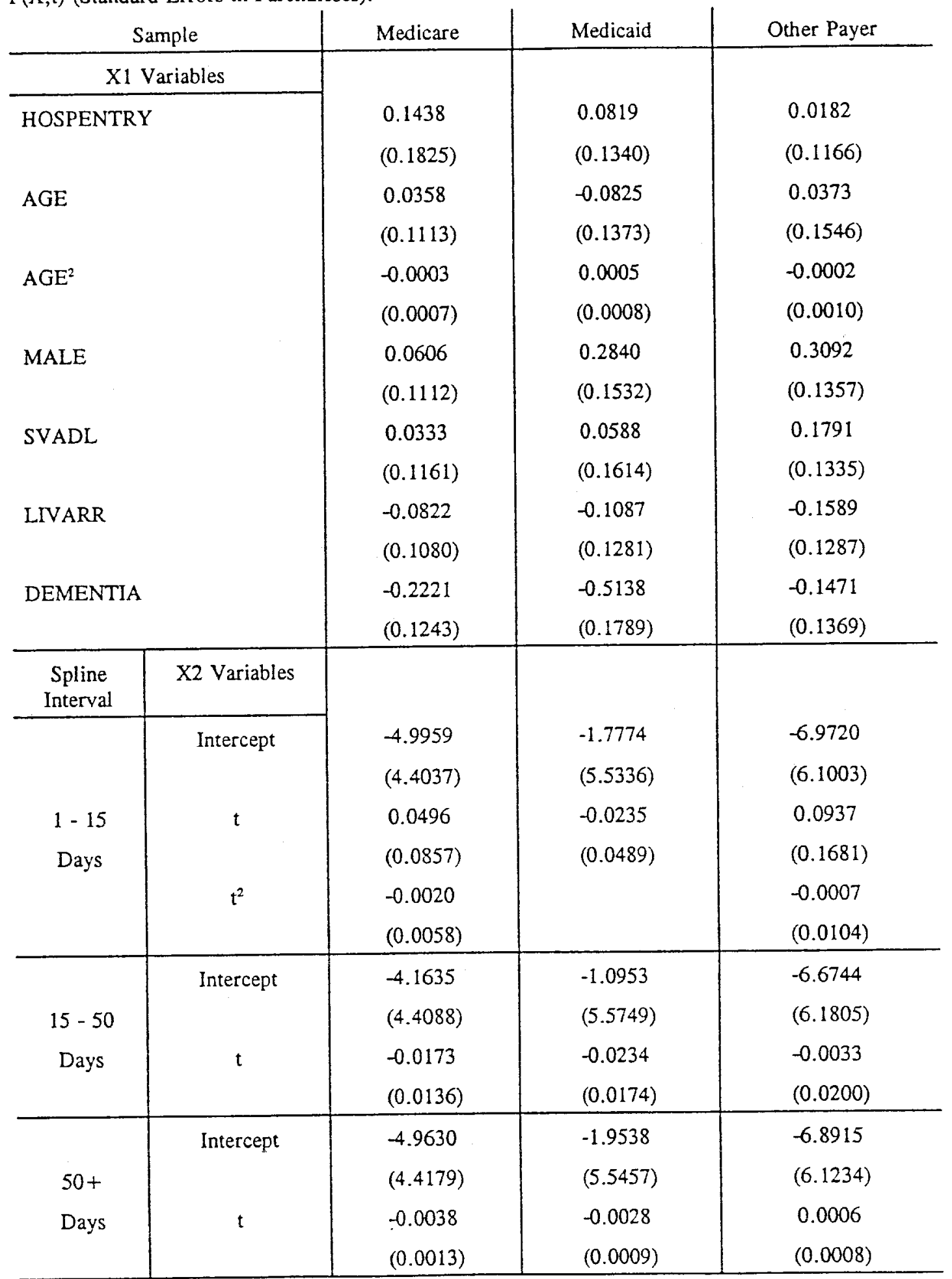


TABLE 3. Parameter Estimates of Nursing Home Spell Duration Probabilities Medicare Incorporating Past Utilization (Standard Errors in Parentheses)

\begin{tabular}{|c|c|c|c|}
\hline Log Likelihood & \multicolumn{3}{|c|}{-2462.210} \\
\hline XI Variables & \multirow{2}{*}{\multicolumn{3}{|c|}{0.1294}} \\
\hline \multirow[t]{2}{*}{ HOSPENTRY } & & & \\
\hline & & $(0.1926)$ & \\
\hline \multirow[t]{2}{*}{ AGE } & & 0.0265 & \\
\hline & & $(0.1169)$ & \\
\hline \multirow[t]{2}{*}{$\mathrm{AGE}^{2}$} & & -0.0003 & \\
\hline & & $(0.0007)$ & \\
\hline \multirow[t]{2}{*}{ MALE } & & 0.0619 & \\
\hline & & $(0.1108)$ & \\
\hline \multirow[t]{2}{*}{ SVADL } & & 0.0504 & \\
\hline & & $(0.1192)$ & \\
\hline \multirow[t]{2}{*}{ LIVARR } & & -0.0731 & \\
\hline & & $(0.1087)$ & \\
\hline \multirow[t]{2}{*}{ DEMENTIA } & & -0.2348 & \\
\hline & & $(0.1263)$ & \\
\hline Spline & $\begin{array}{l}\text { Duration } \\
1-15 \text { Days }\end{array}$ & $\begin{array}{c}\text { Duration } \\
15-50 \text { Days }\end{array}$ & $\begin{array}{l}\text { Duration } \\
50+\text { Days }\end{array}$ \\
\hline \multicolumn{4}{|l|}{$\mathrm{X} 2$ Variables } \\
\hline \multirow[t]{2}{*}{ 2NDSPELL } & -0.1097 & 0.5377 & -0.3033 \\
\hline & $(0.3601)$ & $(0.3072)$ & $(0.3995)$ \\
\hline \multirow[t]{2}{*}{$E$} & -0.0043 & 0.0115 & -0.0003 \\
\hline & $(0.0056)$ & $(0.0059)$ & $(0.0063)$ \\
\hline \multirow[t]{2}{*}{ Intercept } & -4.1759 & -4.9411 & -4.4870 \\
\hline & $(4.7039)$ & $(4.7099)$ & $(4.8220)$ \\
\hline \multirow[t]{2}{*}{$\mathrm{t}$} & 0.0492 & -0.0168 & -0.0037 \\
\hline & $(0.0860)$ & $(0.0137)$ & $(0.0015)$ \\
\hline \multirow[t]{2}{*}{$t^{2}$} & -0.0019 & & \\
\hline & $(0.0058)$ & & \\
\hline
\end{tabular}


Table 4. Quantiles of nursing home durations

\begin{tabular}{|c|c|c|c|c|c|}
\hline \multirow[b]{2}{*}{ Specification } & \multicolumn{5}{|c|}{ Percentile } \\
\hline & 10th & 25 th & 50th & 75th & 90th \\
\hline Utilization Baseline* & 6 & 14 & 31 & 74 & 151 \\
\hline HOSPENTRY = from hospital & 6 & 13 & 27 & 62 & 125 \\
\hline $\mathrm{AGE}=85$ & 7 & 16 & 36 & 92 & 192 \\
\hline MALE $=$ not male & 6 & 15 & 33 & 80 & 166 \\
\hline SVADL $=$ present & 6 & 13 & 29 & 69 & 140 \\
\hline LIVARR = not living alone & 6 & 13 & 29 & 67 & 136 \\
\hline DEMENTIA = Severe & 7 & 17 & 40 & 102 & 218 \\
\hline $\begin{array}{l}E=50 \text { days and } \\
2 \text { NDSPELLS }=\text { is a second spell }\end{array}$ & 6 & 13 & 30 & 82 & 195 \\
\hline
\end{tabular}

- Baseline characteristics are: HOSPENTRY = from community; AGE = 75; MALE; SVADL $=$ no severe impairment present; LIVARR = living alone; DEMENTIA $=$ no severe dementia present; 2 NDSPELL $=$ current spell is not a second spell; $E=100$ days at start of spell. 
TABLE 5. Parameter Estimates of Nursing Home Duration Probabilities $P(X, t)$ (Standard Errors in Parentheses)

\begin{tabular}{|c|c|c|c|c|c|}
\hline Specification & \multicolumn{2}{|c|}{ Model I } & \multicolumn{2}{|c|}{ Model II } & Model III \\
\hline Log Likelihood & \multicolumn{2}{|c|}{-2452.824} & \multicolumn{2}{|c|}{-2455.601} & -2456.706 \\
\hline Spline & $c()$. & $\mathrm{m}()$. & $c()$. & $\mathrm{m}()$. & $\mathrm{m}()$. \\
\hline $\begin{array}{c}\text { Spline } \\
\text { Characteristics } \\
\mu_{1 \mathrm{j}}^{\mathrm{i}} \text { to } \mu_{2 \mathrm{j}}^{\mathrm{i}} \\
\left(\sigma_{1 \mathrm{j}}^{\mathrm{i}}\right)\left(\sigma_{2 \mathrm{j}}^{\mathrm{i}}\right)^{*}\end{array}$ & & & & & \\
\hline-9 to -3 & 0.2696 & 0.2481 & & & \\
\hline (5) (2) & $(0.7749)$ & $(0.9786)$ & & & \\
\hline-5 to -1 & -0.0021 & -1.7788 & & & \\
\hline (2) (1) & $(0.8591)$ & $(2.4553)$ & & & \\
\hline-2 to 0 & 0.7067 & 0.7281 & & & \\
\hline (2) (1) & (1.5061) & (5.1750) & & & \\
\hline-1 to 1 & 0.4191 & 5.2461 & 0.6105 & 2.9974 & 2.9709 \\
\hline (1) (1) & $(0.8073)$ & $(4.6956)$ & $(0.4043)$ & $(0.5772)$ & $(0.5762)$ \\
\hline 0 to 2 & -0.0996 & -2.9570 & & & \\
\hline (1) (2) & $(0.3384)$ & $(3.3422)$ & & & \\
\hline 1 to 7 & 0.1927 & 0.5586 & & & \\
\hline (1) (3) & & & & & \\
\hline
\end{tabular}

- $\mathrm{i}$ takes values $\mathrm{c}$ and $\mathrm{m}, \mathrm{j}$ takes values from 1 to 6 
Table 6: Effect of regime change on duration of nursing home admission.

\begin{tabular}{lll} 
& \multicolumn{2}{c}{ Remaining duration in days } \\
At admission & $\underline{\text { Mean }}$ & \\
with exhaustion splines & 61.6 & 31 \\
exhaustion splines removed & 65.5 & 32
\end{tabular}

At day 17

$\begin{array}{lll}\text { with exhaustion splines } & 66.5 & 32\end{array}$

$\begin{array}{lll}\text { exhaustion splines removed } & 72.0 & 34\end{array}$

At day 95

with exhaustion splines

$95.2 \quad 57$

$\begin{array}{lll}\text { exhaustion splines removed } & 107.1 & 71\end{array}$ 


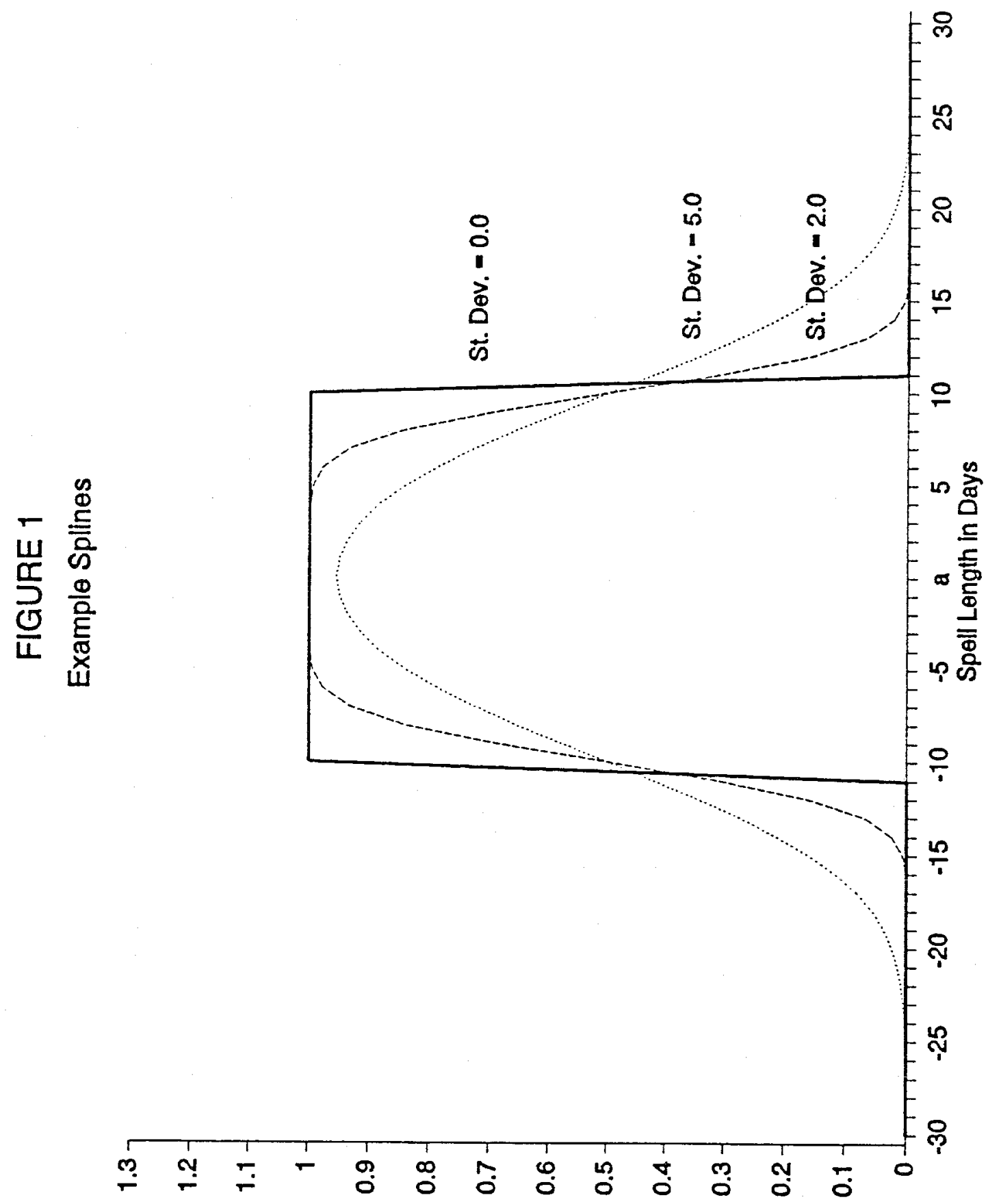

enren ou!jds 


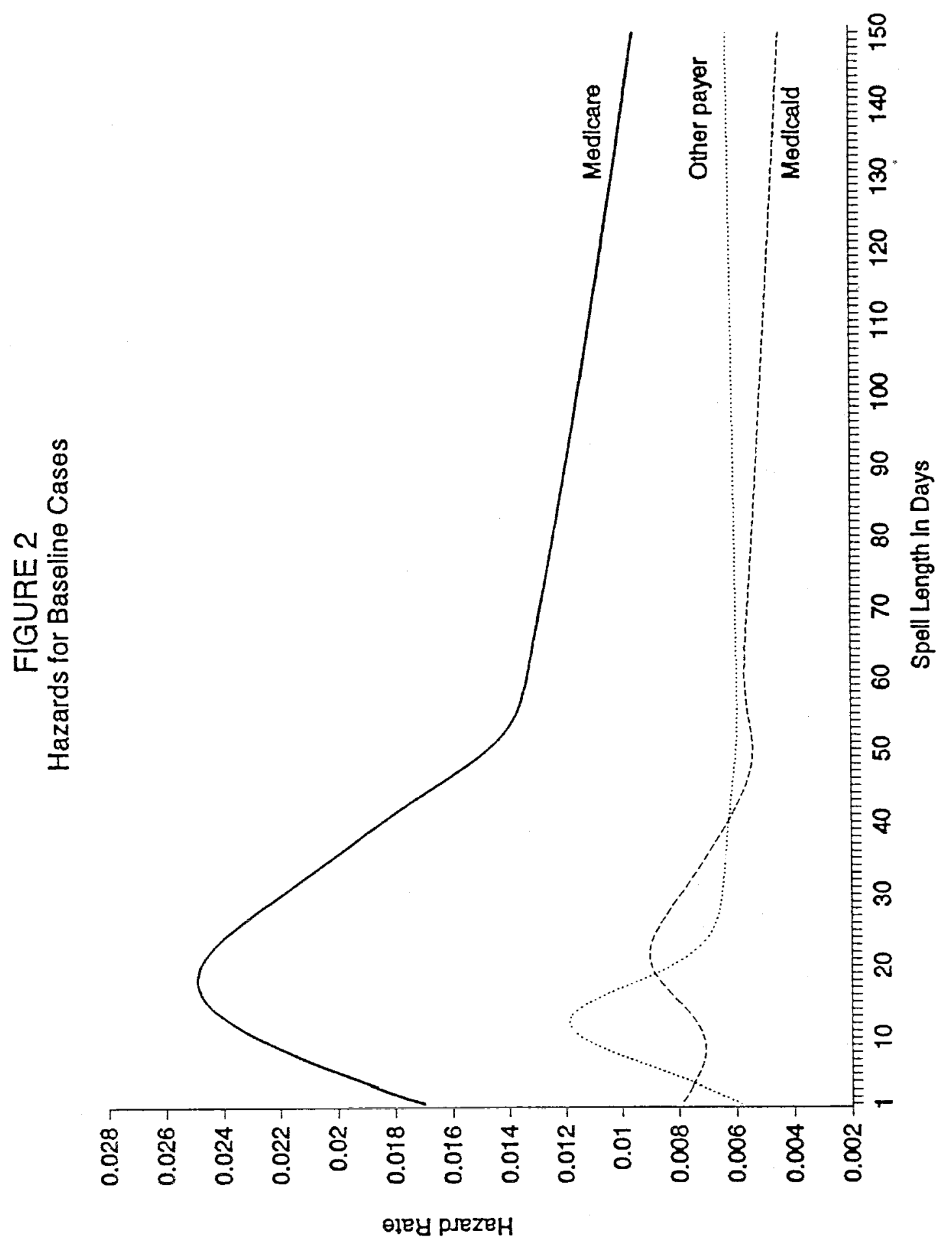




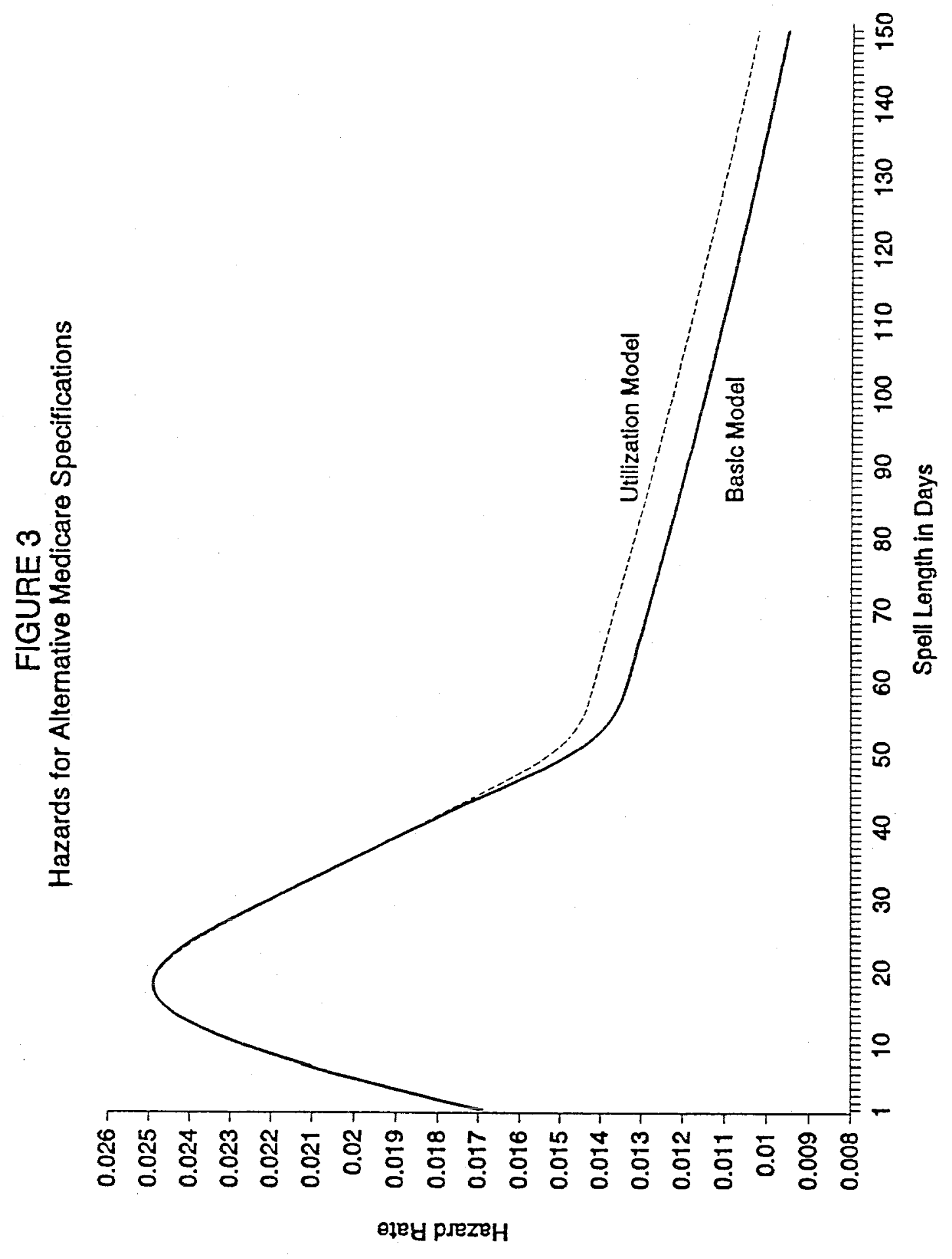




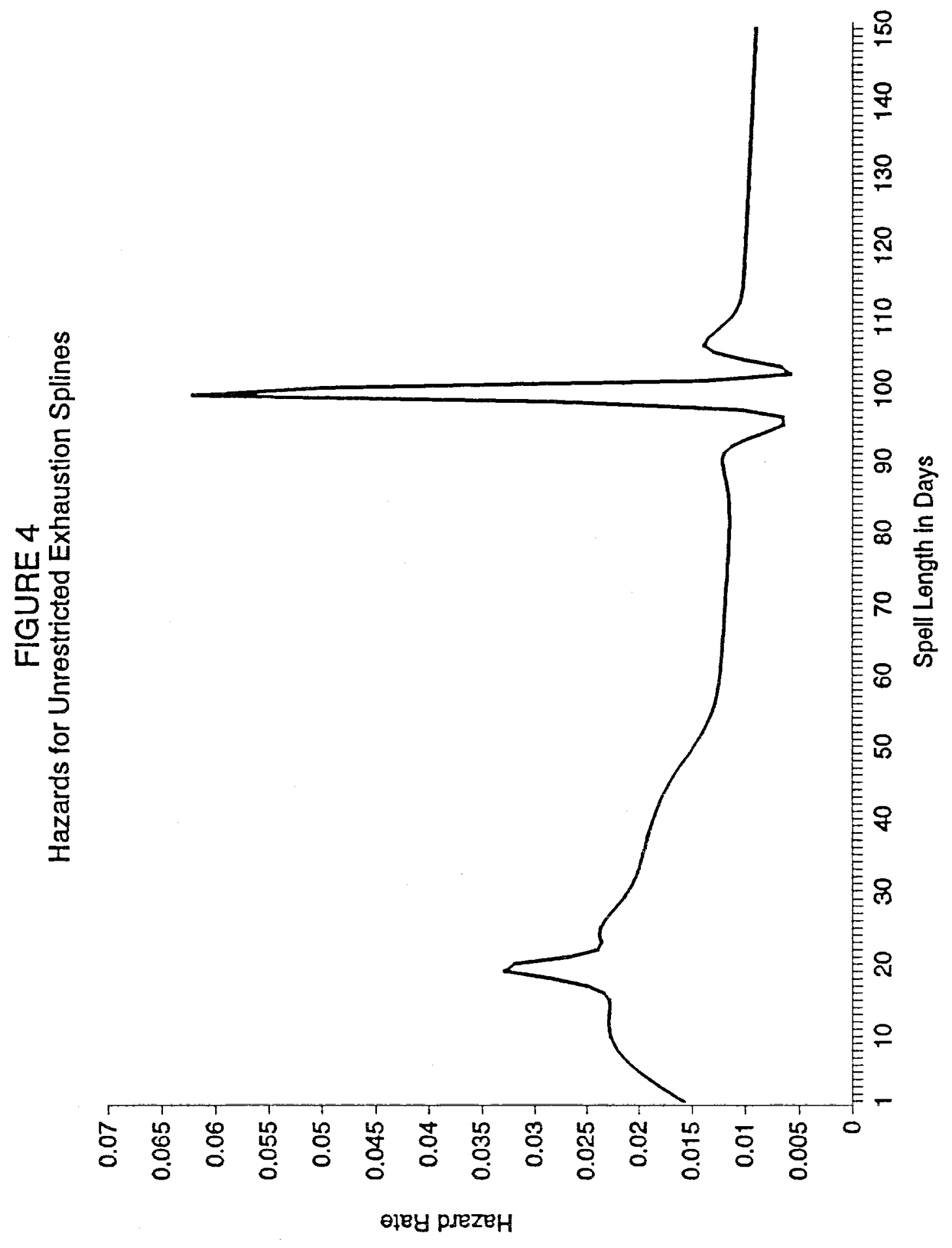




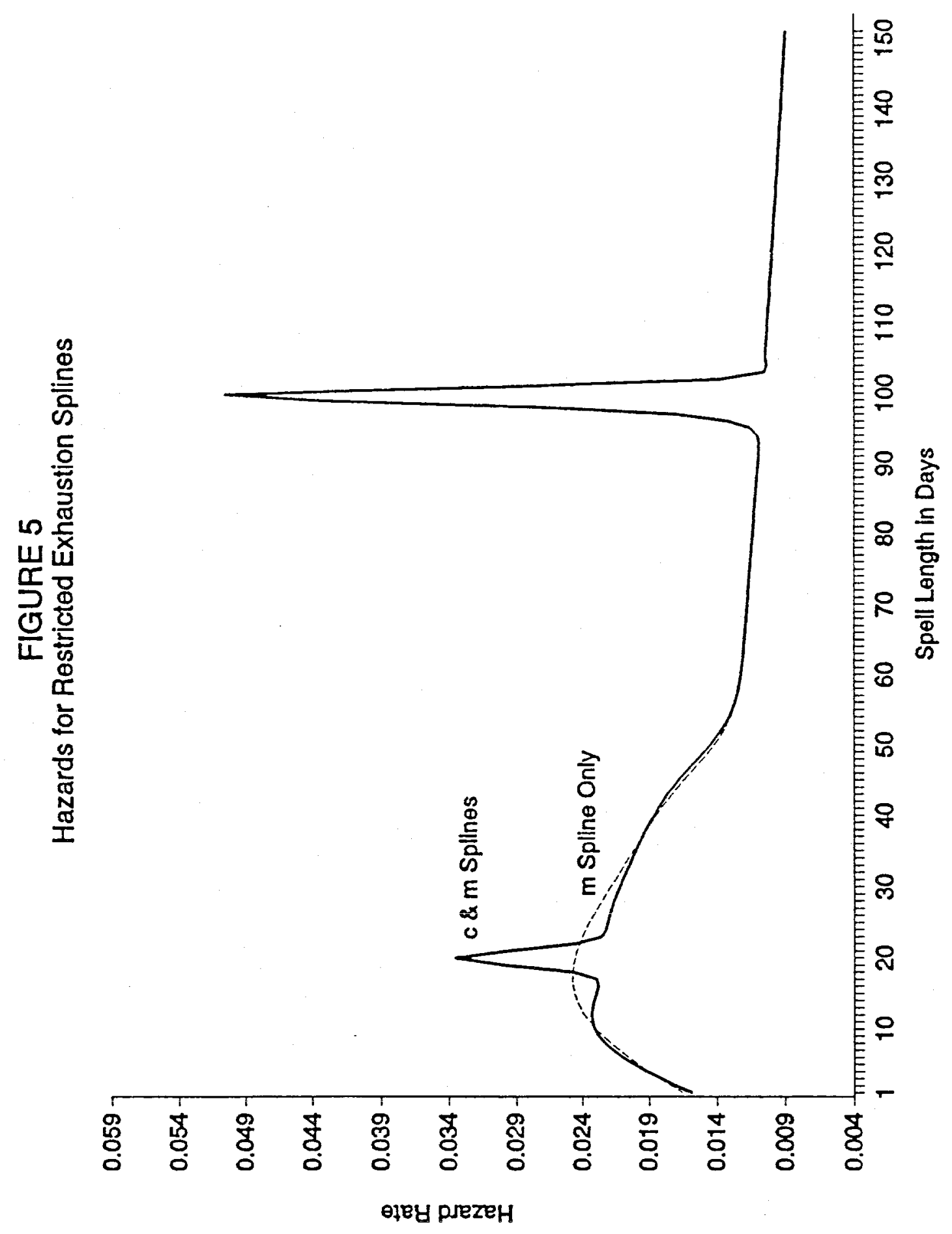

